\title{
A gestão de design social e sustentabilidade de empreendimentos econômicos solidários
}

\section{The management of social design and sustainability solidarity economic enterprises}

\section{SITTA, Seila Cibele I Mestre em Design}

Universidade Estadual de Londrina - UEL

cibelesittap@gmail.com

\section{ALANO, Agda Bernardete I Mestranda em Design}

Universidade Federal de Santa Catarina - UFSC

agda.alano@gmail.com

\section{Resumo}

Este artigo visa demonstrar como a gestão de design contribui com os empreendimentos econômicos solidários, conceituando sustentabilidade e o aproveitamento de tecidos. Para a metodologia utilizou-se a pesquisaação, de natureza exploratória, observação e a entrevista semiestruturada. Como resultado, apresentam-se modelos e aviamentos para as roupas de dormir com o aproveitamento de tecidos.

Palavras Chave: Gestão de design; Susten tabilidade;Empreendimentos econômicos solidários.

\section{Abstract}

This article aims to demonstrate how the management of design contributes to economic enterprises solidarity, conceptualizing sustainability and taking advantage of fabrics. For this method we used is action research, exploratory in nature, observation and semi-structured interview. As a result, presents models and accessories for sleepwear with the harnessing of fabrics.

Keywords: Design management; Sustainability; Solidarity economic enterprises. 


\section{INTRODUC̣̃̃O}

Os empreendimentos econômicos solidários são grupos produtivos que fazem parte do programa de economia solidária, um programa social, o qual atua em âmbito nacional com o objetivo de combater a miséria por meio da geração de trabalho e renda. Cada região, estado ou cidade que trabalha com o programa de economia solidária, se constitui por empreendimentos que são acompanhados semanalmente por assessoras técnicas especialistas do próprio programa, desde a formação até a sua inserção mercadológica. Apesar de todos os empreendimentos passarem por capacitações, estes são inseridos em uma economia dominante, a capitalista, com grande produtividade e competitividade, dificultando sua solidez mercadológica por diversos motivos, como afastamento do mercado de trabalho, nível baixo de alfabetização e cultura, problemas socioeconômicos entre outros.

Diante deste cenário, se torna complexo tanto a visibilidade, como o desempenho mercadológico dos empreendimentos econômicos solidários. Tais empreendimentos não possuem se quer uma identidade visual visando facilitar sua identificação e de seus produtos no mercado, além de fortalecer o programa de economia solidária que ainda é muito desconhecido pela sociedade local.

O empreendimento em estudo é do segmento de vestuário e atua com a confecção de roupas de dormir. Por meio de um estudo de profundidade já realizado anteriormente foi identificada dentre as fragilidades, a falta de aproveitamento de matéria-prima como processo sustentável e inovador para os empreendimentos econômicos solidários. Portanto a questão norteadora desta pesquisa é: como a gestão de design contribui com o empreendimento econômico solidário em relação à sustentabilidade e o aproveitamento de matérias-primas?

Pressupõe-se que com o conhecimento da gestão de design e a clarificação e aplicação dos conceitos de sustentabilidade aplicados ao empreendimento econômico solidário, o mesmo terá melhorias tanto em qualidade de produto, gestão organizacional como em sustentabilidade.

\section{Gestão de Design e Design Social}

A gestão de design tem como objetivo administrar a empresa ou empreendimento em nível estratégico e diagnosticar a sua situação e de seus produtos, definindo melhores processos produtivos, aprimorando produtos e entendendo melhor o mercado para integrá-los com as funções de produção, 
marketing e comunicação da empresa, corrobora o Manual de Gestão de Design (CENTRO PORTUGUÊS DE DESIGN, 1997).

Para Mozota (2011) a gestão de design tem como função identificar e comunicar como o design pode contribuir com o valor estratégico de uma empresa, integrando a gestão de design em nível operacional do projeto (ação), organizacional ou tático (função) ou estratégico (missão). A autora ainda apresenta um estudo sobre a cadeia de valor do Design nas organizações que se divide nos três níveis da Gestão de Design, conforme demonstra o quadro 1.

Quadro 1 - Cadeia de valor do Design.

\begin{tabular}{|lll}
\hline AÇÃO DE DESIGN & FUNÇÃO DE DESIGN & VISÃO DE DESIGN \\
\hline $\begin{array}{l}\text { O valor de diferenciação } \\
\text { do design }\end{array}$ & $\begin{array}{l}\text { O valor de coordenação } \\
\text { do design }\end{array}$ & $\begin{array}{l}\text { O valor de transformação } \\
\text { do design }\end{array}$ \\
\hline $\begin{array}{l}\text { O design é uma } \\
\text { competência econômica } \\
\text { que muda as atividades } \\
\text { primárias na cadeia de valor }\end{array}$ & $\begin{array}{l}\text { O design é uma } \\
\text { competência administrativa } \\
\text { que muda as atividades } \\
\text { primárias na cadeia de valor }\end{array}$ & $\begin{array}{l}\text { O design é uma } \\
\text { competência central } \\
\text { que muda a cadeia do } \\
\text { setor e a visão da indústria }\end{array}$ \\
$\begin{array}{l}\text { Marketing de marca } \\
\begin{array}{l}\text { Produção } \\
\text { Comunicação }\end{array}\end{array}$ & $\begin{array}{l}\text { Estrutura } \\
\text { Gestão de tecnologia } \\
\text { Gestão de inovação }\end{array}$ & $\begin{array}{l}\text { Estratégia } \\
\text { Gestão de conhecimentos } \\
\text { Gestão operacional do } \\
\text { design }\end{array}$ \\
\hline
\end{tabular}

Fonte: Mozota (2011, p. 310).

No quadro é apresentado o valor do design enquanto diferenciador, coordenador e transformador, relacionado à competência econômica, administrativa e de visão, classificado nos níveis operacional, tático e estratégico da gestão de design.

Este gerenciamento também pode ser aplicado no design social e/ou para causas sociais, que tem como conceito a

[...] materialização de uma ideia que propõe um processo de transformação na sociedade. Procura desenvolver estratégias de comunicação (visuais inclusive, mas não exclusivamente) que permitam compactar um conceito e difundir conhecimento visando sempre uma transformação social (MARTINS; MERINO, 2011, p. 71).

Lima e Martins (2011 apud BRAGA, 2011, p. 115) versam sobre o design social como

[...] uma abordagem de projeto que implica tanto 
metodologias participativas como motivações projetuais e consequências sociais do processo de design. É possível afirmar ainda que o design social também promove valores como sustentabilidade e desenvolvimento sociocultural.

Para Bonsiepe (2006), o "design humanista" tem como função interpretar e desenvolver propostas emancipatórias às necessidades de grupos sociais, com enfoque para os excluídos, os discriminados e menos favorecidos economicamente, não utilizando o design apenas como ferramenta dominadora para a sustentação do consumo.

Nesse sentido, o design pode contribuir ativamente com a responsabilidade social, por meio da gestão de design, de processos e de mudanças comportamentais.

Martins e Merino (2011, p. 71-72) relata que

\begin{abstract}
[...] a busca por consciência coletiva o processo de criação visa otimizar performance, inovação, qualidade, durabilidade, aparência e custos referentes cada produto, ambiente, informação e marca. a materialização das ideias é o resultado da preocupação em desenvolver solução adequada para cada projeto, reforçando a mensagem, entrelaçando códigos e linguagens, enaltecendo o sentimento e considerando necessidades e desejos de seus público.
\end{abstract}

O design junto de sua gestão tem a preocupação de comunicar e criar condições para que o seu público entenda sua mensagem e perceba seus benefícios, por meio de estratégias e estudos multidisciplinares.

\title{
A indústria da Moda, a Sustentabilidade e o Ecodesign
}

A moda em sua relação com a indústria do vestuário segue o que é proposto pelas tendências e nesse sentido incentiva o consumo estimulado pela obsolescência programada, parecendo utópico pensar numa aproximação entre moda e sustentabilidade. Relacionando aos três pilares da sustentabilidade definido por Sachs (2002, p. 35) uma sociedade é sustentável, "ao atender, simultaneamente, aos critérios de relevância social, prudência ecológica e viabilidade econômica, os do desenvolvimento sustentável". Hoje exemplos de empresas de moda no Brasil e no mundo podem ser destacados em ações que 
envolvem a sustentabilidade na moda, porém algumas dessas ações se dão por iniciativas puramente mercadológicas.

Para Fletcher e Grose (2011, p. 138) "produtos que apresentem inovação em sustentabilidade, são definidos e apresentados como um diferencial da marca, onde a intenção seria de elevar o aumento das vendas", porém isso não impossibilita de que as empresas atuem de forma legítima uma vez que tratando-se de empreendimentos econômicos solidários onde a própria natureza da empresa e constituída a partir de um fim social.

Vezzoli (2008) afirma que a sustentabilidade deve ser entendida como ato de projetar produtos, serviços e sistemas com um baixo impacto ambiental e uma alta qualidade social.

Projetos de geração de renda buscam a sustentabilidade, principalmente a econômica e a social, em comunidades de baixa renda, por meio da criação de produtos inovadores, ou ainda, pelo melhoramento dos processos produtivos, que na maioria das vezes é o artesanal. Uma das características destas comunidades é se apresentarem, de maneira geral, como possuidoras de baixo conhecimento tecnológico e alto valor cultural, relata Costa (2009).

Tomando como ponto de partida o aspecto produtivo da moda, de acordo com uma visão operacional, o design na sua relação com a moda pode atuar de acordo como os valores de diferenciação, coordenação e transformação. Neste sentido torna-se necessário relacionar a gestão de design aos conceitos do ecodesign.

Manzini e Vezzoli (2002) tratam o ecodesign a partir da metodologia Life Cicle Design, como uma maneira de projetar considerando toda a cadeia produtiva, assim definida pela pré-produção, produto, distribuição, uso e descarte. Nesse sentido a ecodesign está relacionado ao ato de projetar, porém seu foco não está apenas no produto, mas em toda a cadeia produtiva envolvendo uma análise desde a entrada dos recursos necessários para a produção, à verificação do processo produtivo, bem como a análise do resultado que é representado não somente pelo produto, mas pelo que é gerado como rejeito, no caso as sobras de matéria prima.

Porém se tratando de empreendimentos econômicos solidários deve se levar em conta que sua economia possui um desenvolvimento abaixo da realidade das indústrias do vestuário, significando possibilidades de pequenas implementações de gestão de design, considerando o potencial de habilidades técnicas e financeiro do empreendimento, bem como a compreensão entre os envolvidos sobre o que é a sustentabilidade. A gestão de design poderá 
possibilitar desde cedo à percepção do que é reutilizar ou dar um destino mais adequado para o que seria rejeito, sendo uma maneira de produzir com responsabilidade ambiental desde sua formação.

\section{Ecoeficiência na Moda}

O prefixo "eco", do termo ecoeficiência, refere-se à ecologia, que associado à economia, converge no sentido da eficiência ambiental com desenvolvimento econômico (LEHNI, 1997), assim aplicado à indústria, será refletido na maximização dos recursos não só para a produção, mas na escolha de materiais de baixo impacto, emissão de efluentes não tóxicos, entre outros.

A gestão de design depende de outras esferas de decisão que no caso de empreendimentos solidários depende, não somente das pessoas que produzem, mas também das políticas ou mesmo da sociedade organizada (MANZINI; VEZZOLI, 2002). Torna-se evidente que alcançar níveis desejáveis de produção e uso com menor impacto ambiental depende em primeiro momento da compreensão de todos os envolvidos. Nesse sentido considerando um pequeno empreendimento a gestão de design é capaz por meio de uma ação estratégica relacionar a maximização do uso dos recursos com a geração de valor para empresa, e nesse sentido o valor não somente como ganho para empresa emb lucratividade pelo aproveitamento dos recursos materiais, mas como valor enquanto benefício para o usuário e para a sociedade.

$\mathrm{Na}$ indústria do vestuário uma das possibilidades na maximização dos recursos está relacionado com o aproveitamento de seus insumos e nesse caso destaca-se o uso do tecido. No caso dos empreendimentos econômicos solidários, esse aspecto se torna ainda mais importante, considerando a sua baixa capacidade de investimento econômico.

A maneira de como é aproveitado o tecido no empreendimento, requer um planejamento que envolve o estudo de encaixe dos moldes sobre o tecido. A relação entre a área do molde e a área do tecido, resulta no grau de aproveitamento de tecido. Empresas de médio e grande porte utilizam de sistemas automatizados que incluem a construção da modelagem do vestuário e o estudo de encaixe via sistema CAD (Computer Aided Design), termo em inglês que significa desenho assistido por computador. Esse tipo de sistema, otimiza tempo para o estudo de encaixe, bem como a eficiência no aproveitamento de tecido. Esta tecnologia está distante da realidade de um empreendimento econômico solidário, considerando o seu tipo de produção que é a artesanal. Portanto é necessário que se encontre novas alternativas 
visando o melhor aproveitamento do tecido.

Segundo Martins e Merino (2011) a partir de projetos práticos é possível promover a diferenciação nas empresas do setor do vestuário por meio de produtos e processos com maior eficiência no consumo de matéria-prima e energia, gerando resultados no ponto de vista estético quando associado ao produto, e lucrativo para o empreendimento. Esta percepção pode ser aplicada como estratégia nos empreendimentos econômicos solidários.

\section{METODOLOGIA}

Para este estudo foi realizada uma pesquisa aplicada, a qual tem o enfoque às dificuldades presentes nas atividades cotidianas dos empreendimentos econômicas solidários. A pesquisa aplicada visa à elaboração de diagnósticos, por meio da identificação de problemas e a busca por soluções por meio de métodos e técnicas adequadas, corrobora Thiollent (2011).

O método utilizado para a estudo foi a pesquisa-ação, pesquisa de contexto organizacional, por estabelecer um relacionamento integrado entre a pesquisa e os pesquisados. Thiollent define a pesquisa-ação como:

[...] um tipo de pesquisa social com base empírica que é concebida e realizada em estreita associação com uma ação ou com a resolução de um problema coletivo e no qual os pesquisadores e os participantes representativos da situação ou do problema estão envolvidos de modo cooperativo ou participativo (THIOLLENT, 2011, p. 20).

A pesquisa realizada se caracteriza como exploratória e descritiva. Foram utilizadas como técnicas de coleta de dados, a observação direta intensiva e a entrevista. Marconi e Lakatos (2006), diz que a observação é uma técnica que se utiliza dos sentidos para obter informação e deve estar em contato mais direto com a realidade. Esta é classificada como método qualitativo e pode ser quantificável, corrobora Richardson (2009).

A entrevista tem como objetivo a obtenção de dados diversos sobre a vida social com profundidade, pois com esta técnica é possível captar a expressão corporal do entrevistado, sua tonalidade de voz e ênfase das respostas. Para Gil (2008, p. 111), "a entrevista é seguramente a mais flexível de todas as técnicas de coleta de dados de que dispõe as ciências sociais". Na pesquisa foi utilizada a entrevista semiestruturada, na qual o "entrevistado tem a liberdade 
para desenvolver cada situação em qualquer direção que considere adequada" (MICHEL, 2009, p. 68-69).

\section{Apresentação do Empreendimento Econômico Solidário em estudo}

O empreendimento econômico solidário de vestuário em estudo formouse em Fevereiro de 2007. O mesmo é constituído por duas mulheres, cuja idade varia entre 50 e 65 anos. Toda a estrutura inicial como máquinas de costura, mesa de corte, tecidos, entre outros, foi fornecida pelo programa de economia solidária local e atualmente o empreendimento já possui uma máquina de costura própria, conquistada pelo sucesso de suas vendas. O espaço de produção do empreendimento é localizado em cômodo de uma casa paroquial. Neste empreendimento são produzidas roupas para dormir especificamente em malha de poliviscose lisa e estampada, tais como: pijamas femininos, masculinos e infantis; baby-dolls; camisolas; atendendo com a numeração padrão $P, M, G$ e GG e produtos sob encomenda, conforme apresentado nas figuras abaixo.

Figura 1 - Produtos - roupas de dormir

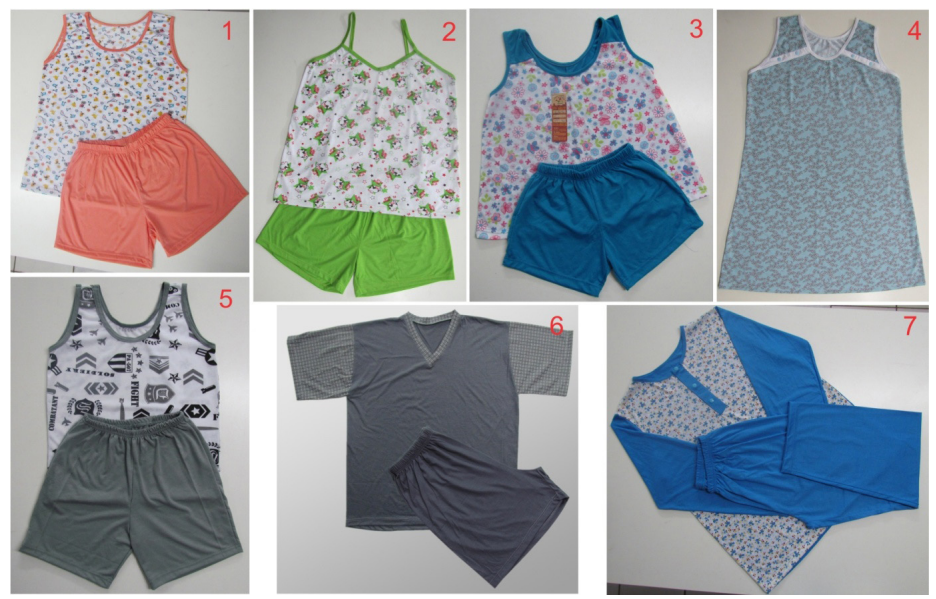

Fonte: Autora (2013).

O empreendimento produz para o público feminino o modelo regata (1) com o ombro maior, que atende idades diversas, porém tem grande aceitação pelos idosos, pelo conforto e segurança que o produto proporciona. O modelo baby doll (2), o regata de ombro menor (3), para crianças, a camisola (4) e o pijama meia estação de manga comprida e calça (7). Já para o público masculino é produzido o modelo regata (5) para todas as idades, mas tem grande aceitação para crianças e o modelo camiseta e shorts (6) para todas as idades, mas com maior aceitação para os adultos. 


\section{DISCUSSÃO E RESULTADOS}

Diante do cenário apresentado do empreendimento econômico solidário de roupas de dormir, percebem-se diversas fragilidades, tais como: espaço físico, falta de equipamentos próprios, falta de capacitação em relação à modelagem, corte e aproveitamento dos tecidos e limitação criativa para novos modelos. Porém neste estudo a gestão de design dará enfoque ao gerenciamento da fragilidade sobre o desperdício em relação à matéria-prima e à falta de aproveitamento das sobras dos tecidos, sendo este não proposital e sim por falta de visão organizacional e empreendedorismo, além da ausência de conhecimento sobre o conceito de sustentabilidade, ecodesign, ecoeficiência e seus benefícios. As outras fragilidades serão gerenciadas em um próximo estudo.

Verificou-se junto das integrantes do empreendimento que com as sobras dos tecidos, seria possível criar ornamentos e modelos aplicáveis nas roupas de dormir, além de criar acessórios que possuam relação com descanso noturno, como máscaras para dormir, e que o empreendimento possa desenvolver, por capacidade produtiva e respeito aos princípios da economia solidária.

Durante o planejamento da gestão de design, foi utilizado como estratégia convidar uma aluna do curso de design de moda para participar do projeto do empreendimento econômico solidário, que pudesse orientar o grupo em relação ao aproveitamento dos tecidos e das sobras dos mesmo, além de clarificar sobre conceitos de sustentabilidade e sugestão de criar modelos de roupas de dormir utilizando os critérios de sustentabilidade e aproveitamento.

Na figura 2 são apresentados os dois modelos padrão de roupas de dormir feminino, sendo este confeccionado para o público infantil, juvenil, adulto e idosos.

Figura 2 - Modelos padrão de roupa de dormir feminina/ masculina.

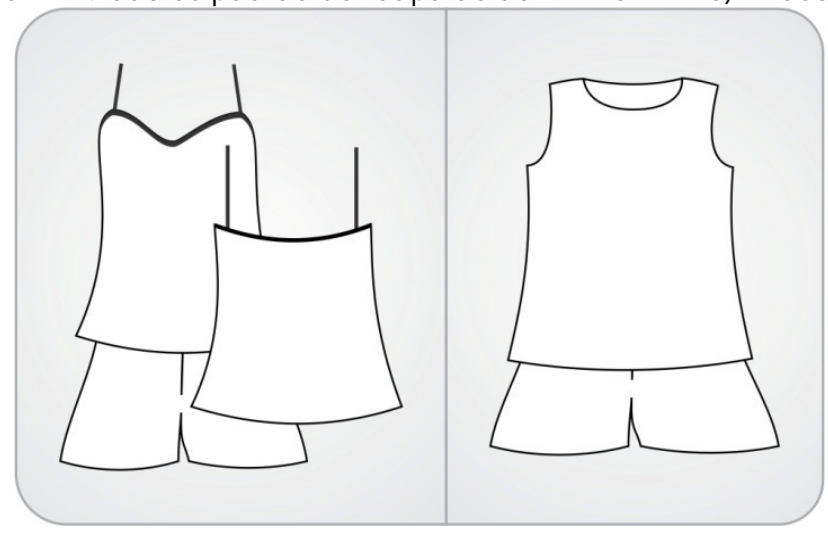

Fonte: Autora (2013). 
O modelo baby doll é uma roupa de dormir feminina, sendo desenvolvida para o público de infantil, juvenil e adulto com ajustes específicos para cada molde. E o modelo regata é um padrão tanto para roupas femininas, quanto masculinas, também com os ajustes necessários para cada público e tamanho. Este modelo é muito confeccionado para idosos por ter mais confortável e proteger mais o corpo.

Na figura 3 são apresentados ornamentos que poderão ser aplicados nas roupas de dormir, valorizando ainda mais o produto e utilizando parte das sobras de tecidos.

Figura 3 -Modelo roupa de dormir baby doll

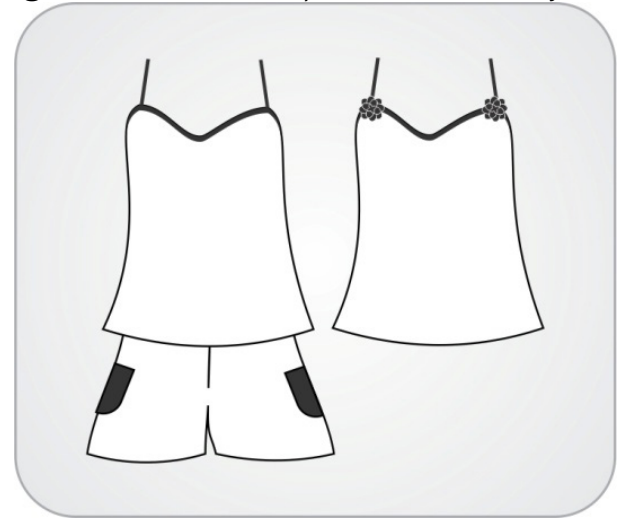

Fonte: Autora (2013).

Poderá ser aplicado bolsos nos shorts dos baby dolls para valorização de sua função estética e os fuxicos nas blusas. Estas duas novas alternativas são de baixa complexidade para produção, sendo possível o desenvolvimento pelas integrantes do empreendimento, além de estimular a criatividade para novos apliques. Os dois apliques não precisam estar presentes em uma única roupa de dormir, o cliente poderá escolher se quer o bolso ou o fuxico em seu modelo.

Figura 4 - Modelo roupa de dormir baby doll.

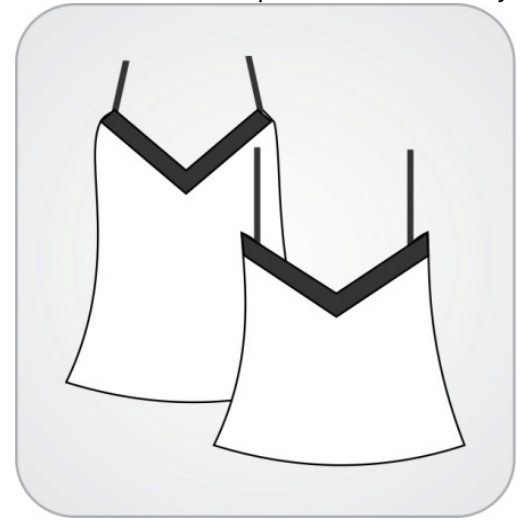

Fonte: Autora (2013). 
Já nesta proposta de modelo, é necessária a utilização de sobras maiores, devido ao sentido do tecido, para que não haja desconforto em sua utilização. Como apresentado na figura 04, o modelo possui uma parte que é costurada junto da blusa do baby dolls, proporcionando um decote diferenciado. O mesmo acontece nas costas. Este modelo já demanda de moldes específicos para que o produto final tenha uma boa aparência e conforto. Neste caso, pode ser levado mais tempo para a confecção do modelo, sendo necessário recalcular seu preço de venda. Esta peça ainda pode ser combinado com o shorts liso ou com bolso, proposto anteriormente.

A figura 5 apresentará o modelo regata, que é utilizado tanto para o público feminino, quanto para o masculino.

Figura 5 - Modelo roupa de dormir feminina/masculino

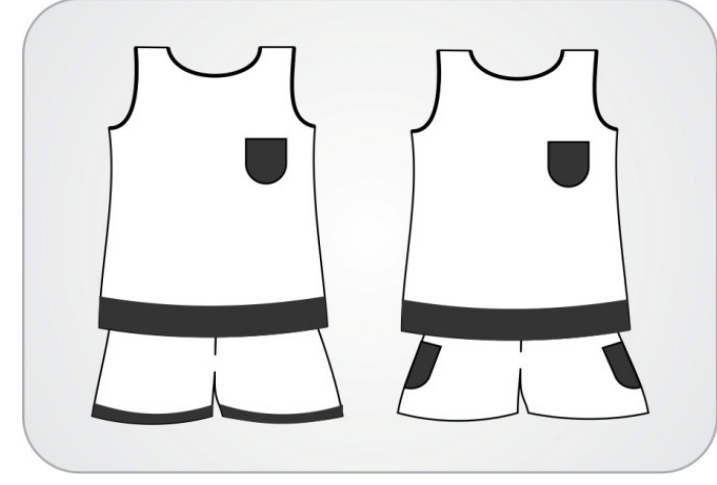

Fonte: Autora (2013).

Esta proposta traz diferenciais no produto, porém todos com baixa complexidade para sua confecção. Na blusa já é padrão ter galão na gola e cavas, neste caso seria inserido no modelo, o bolso e o barrado inferior na camiseta e o barrado no shorts. Já na outro modelo teria bolso tanto na camiseta, quanto no shorts, porém o mesmo não teria o barrado. Neste caso, existe um ótimo aproveitamento de tecido, devido à orientação do mesmo e seus tamanhos.

Na figura 7 é apresentado a mascara de dormir para ser confeccionada com as sobras dos tecidos.

Figura 7 - Máscara para dormir

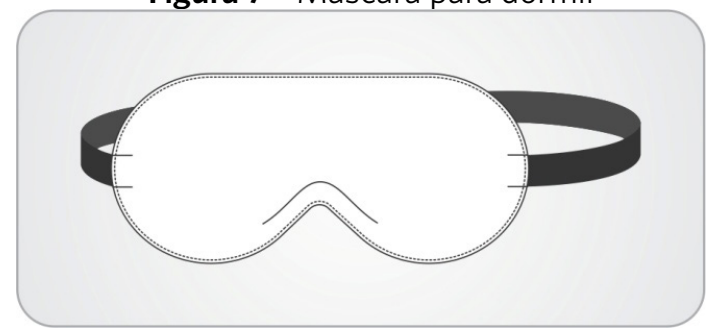

Fonte: Autora (2013). 
Como este produto está relacionado com as roupas de dormir, o empreendimento econômico solidário poderá confecciona-la sem desrespeitar os princípios que regem a economia solidária, proporcionando mais um produto para a linha do empreendimento, e uma nova opção para o seu público.

Portanto, a partir de modelos de roupas de dormir padrão confeccionado pelo empreendimento econômico solidário, foi possível com a apresentação sobre conceitos de sustentabilidade para as integrantes do empreendimento, a criação de algumas propostas de modelos e acessórios para o aproveitamento dos tecidos que sobram entre um corte e outro dos moldes das roupas de dormir. Nesse processo pode-se ainda ser explorada a composição entre os tecidos lisos e estampados.

\section{CONCLUSÃO}

Com a compreensão e adoção dos conceitos aprendidos sobre sustentabilidade, o empreendimento econômico solidário, terá um aproveitamento de quase $100 \%$ de sua matéria-prima, evitando o desperdício de tecido, prejuízo financeiro, contribuição para a geração de menos lixo, assim, colaborando para a diminuição do impacto ambiental.

Com a atuação da gestão de design focada ao empreendimento econômico solidário e em sua fragilidade evidenciada neste estudo, a de desperdício de matéria prima, obtêm como resultado que as sobras de tecidos geradas entre os cortes dos moldes das roupas de dormir, poderão ser aproveitadas, fabricando ornamentos como fuxicos, laços, bolsos entre outros que poderão ser aplicados nas roupas de dormir, valorizando-as com pequenos detalhes que proporcionam diferencial em relação ao aspecto estético e criativo do vestuário. Com tais sobras, também se torna possível desenvolver novos modelos, mantendo a mesma qualidade e estética de um produto que não foi confeccionado por meio do aproveitamento.

Nesse sentido, a gestão de design se apresenta ativa em seus três nível (estratégico, tático e operacional) proporcionando para o empreendimento possibilidades de crescimento e desempenho de maneira mais estável, além da atuação social do design, para com o projeto, os integrantes e sociedade. 


\section{REFERÊNCIAS}

BONSIEPE, G. Design and democracy. Design Issues, Chicago, v. 22, n. 2, 2006. Disponível em: <http://www.guibonsiepe.com/pdffiles/ Democracy_and_Design.pdf>. Acesso em: 14 jun. 2013.

BRAGA, M. C. (Org.). O papel social do design gráfico. História, conceitos \& atuação profissional. São Paulo: Senac. 2011.

CENTRO PORTUGUÊS DE DESIGN. Manual de gestão de design. Porto: Porto Editora, 1997.

COSTA, M. B. Contribuições do design social: como o design pode atuar para o desenvolvimento econômico de comunidades produtivas de baixa renda. In: SIMPÓSIO BRASILEIRO DE DESIGN SUSTENTÁVEL, 2., 2009, São Paulo. Anais... São Paulo, 2009.

FLETCHER, K. GROSE, L. Moda e sustentabilidade: design para mudanças. São Paulo: SENAC, 2011.

GIL, A. C. Métodos e técnicas de pesquisa social. 6. ed. São Paulo: Atlas, 2008.

MARCONI, M. A.; LAKATOS, E.M. Fundamentos de Metodologia Científica. 6. ed. São Paulo: Atlas, 2006.

LEHNI, M. Applying eco-efficiency: the key to competitivness in the new century? In: PENEDA, C.; FRAZÃO, R. (Ed.). Eco-efficiency and factor 10. Lisboa: INETI, 1997. p. 13-19.

MANZINI, E.; VEZZOLI, C: Product-service systems and sustainability: opportunities for sustainable solutions. Paris: UNEP-United Nations Environment Programme, 2002.

MARTINS, R.; MERINO, E. Gestão de design como estratégia organizacional. Londrina: EDUEL, 2011.

MICHEL, M. H. Metodologia da investigação científica para ciências sociais aplicadas. São Paulo: Atlas, 2009.

MOZOTA, B. B. Gestão do design: usando o design para construir valor na marca e inovação corporativa. Porto Alegre: Bookman, 2011.

RICHARDSON, R. J. Pesquisa social: métodos e técnicas. 4. ed. Rio de 
Janeiro: 2AB, 2009.

SACHS, I. Caminhos para o desenvolvimento sustentável. Rio de Janeiro: Garamond, 2002.

THIOLLENT, M. Metodologia da Pesquisa-ação. 14.ed. São Paulo: Cortez Editora, 2011.

VEZZOLI, C. O cenário do design para uma moda sustentável. Em: PIRES, Dorothéia (Org.). Design de Moda: olhares diversos. Barueri: Estação das Letras e Cores Editora, 2008. p. 197-205..

Recebido em: 16/04/2013 Aceito em: 19/05/2013 